\title{
The mental state we are in: morale and psychiatry*
}

\author{
Chris Thompson
}

\section{Selection or attrition?}

In this lecture I will ask: is morale poor among doctors? If it is (and let us for a moment assume that it might be), why is it that? If it is worse recently then is the deterioration an inevitable part of the process of rapid change in the National Health Service (NHS)? Is it, on the other hand, remediable?

Is low morale a selection effect? Are we, in other words selecting a bunch of wimps for medical school on the basis of academic ability rather than hardiness in the face of stress? This was the view of a friend of mine who is an exsoldier. "Perhaps", he said, "we should return to the good old days when medical students were chosen for prowess on the rugby pitch or in rowing boats". Quite apart from the sexism of such a selection policy I doubt that it would make any difference because medical schools are already able to select the best academic students and then apply further criteria for hardiness (Duke of Edinburgh schemes, etc) such is the attraction of medicine before exposure to the reality.

\section{Effect and neglect}

Does it matter if morale is low? In the military world, and indeed in commercial airlines and the emergency services, morale has been found to affect the operational abilities of the organisation. In medicine, as in the army, that probably means that people die unnecessarily if doctors have low morale. It also has the effect of reducing the individual doctor's readiness for change, and it increases the loss of trained staff and therefore the wastage of scarce resource.

Against this background one would expect the morale of the NHS workforce to be high on the agenda of the personnel departments of all NHS

This article is a digest of the first open lecture of the Professors of Psychiatry club, which was given at the Royal College Annual Meeting in Bournemouth in July 1997. trusts, and of the National Association of Health Authorities and Trusts, the NHS Executive and the Department of Health. It is astonishing. therefore, that although so much has been done in the 'reformed' NHS to reduce wasted resource and to increase efficiency the employing organisations have only recently started to apply themselves to the subject.

\section{Is there a problem?}

My own interest in this stems from four years of being the Registrar of the College in which role I have often sat at my desk in Belgrave Square and read letters from hard-pressed medical directors asking how to find a new consultant and almost always referring to the low morale of their colleagues. Or the letters have referred to the acrimony with which the yearly contract negotiations are carried out. Then there are the letters from senior psychiatrists who have built up a service from scratch over decades who feel that their efforts, experience and remaining energies are systematically denigrated by carpet-bagging young managers with no idea of the nature of the business they have so recently been hired to run. Often these doctors are on the point of taking their early retirement.

This is a state of affairs that has also worried consecutive presidents and so Dr Kendell has recently carried out a survey of consultants who retired early in 1995 and 1996 (Kendell \& Pearce, 1997). There were at least 102 early retirements in that time which (with a further 'uncertain group') suggests the real number to be 60 to 70 a year. There are 457 unfilled consultant posts altogether so the early retirements represent a significant contribution to this number. But why do people choose to go early? In the questionnaire which was sent to these doctors $70 \%$ cited bureaucracy and $52 \%$ interference by managers in clinical decisions as being among their reasons for going. It is not therefore the core clinical job which they do not like, but the way in which the NHS has developed. 


\section{Morale and mental health}

One indicator of morale is mental health. If highly intelligent, professionally motivated people have high rates of mental ill health (and indeed suicide) it suggests that there may be something wrong with their work environment. We have very clear evidence for poor mental health in the profession. A report entitled The Mental Health of the NHS Workforce' published quietly in March 1996 by the Sheffield Institute of Work Psychology (Borrill et al, 1996) shows just how poor it is in most but not all professional groups. The researchers used the General Health Questionnaire (GHQ-12) to obtain ratings from 12000 respondents and compared 'caseness' rates between various NHS professional groups and also between NHS staff and similar professional groups in the general population.

In the total NHS sample the average caseness rate was $26.8 \%$. This was highest in NHS managers $(33.4 \%)$, followed by nurses $(28.5 \%)$, doctors $(27.8 \%)$ and the professions allied to medicine $(26.7 \%)$. For comparison, the background rates for those in non-NHS work were only $17.8 \%$ and rates comparable to those in the NHS are only usually seen in the unemployed (30.2\%). In other words it is better for your mental health to be unemployed rather than to go on working as an NHS manager. It is an even better idea to get a job as a non-NHS manager $(17.2 \%)$. With such highly stressed managers can we really expect them to be interested in improving the morale of those they manage?

The rates among doctors were higher among junior and consultant staff and lower among non-consultant career grade staff. They were highest among female junior doctors $(40.8 \%)$ and female consultants (37.2\%). So it appears that the problem of morale in the NHS is widespread and serious.

\section{Maintaining morale}

What factors determine morale? Again we can find some clues from the NHS workforce survey. The researchers found correlations between the subjects' perceptions of influences on their morale and their actual GHQ caseness. They were able to rank these influences by the strength of the association. Seven factors were found to be significant and I will discuss each of them in priority order in relation to the way they might operate on us as psychiatrists.

\section{High work demands and insufficient resources}

This had the strongest association with caseness and will affect particularly those who cannot control their workload according to their re- source, for example the psychiatrist who is on call for a geographically defined population without limit of commitment. It is when you are trying to find a bed in the middle of the night that your morale is most likely to plummet. There is a clear resource problem in mental health services and the last Secretary of State, Stephen Dorrell, quite explicitly agreed with the College's analysis of this.

At the same time the demands for high-quality services have increased - the Patient's Charter is just one reason for this. The penalties for a psychiatrist getting it wrong have also increased, producing a highly threatening environment in which to practise. Recently psychiatrists who have been judged retrospectively to have made honest non-negligent clinical errors have been subjected to public humiliation in the press following independent inquiries. Now that the confidential enquiry is working effectively these detrimental ad hoc inquiries must clearly cease as soon as possible.

\section{Role ambiguity}

Clinical role differentiation within the multidisciplinary team can be an example of this. Most teams nowadays work to differentiated roles, each individual practising what they have been trained to do. But some still seem to pretend that everyone can do the same job and so produce role ambiguity. These teams are not only less effective, they might also be expected to produce low morale, especially in the most highly qualified staff. Who, after all, is the leader of the team? Legally, the medical responsibility is clearly at variance with the idea that any member of the team can be the leader, since doctors are legally responsible for ensuring the adequacy of any non-medical interventions including nursing and occupational therapy. This is even true where the interventions take place outside the statutory sector (e.g. in a mental nursing home run by a voluntary group). Such ultimate responsibility without authority is a recipe for anxiety, to say the least.

\section{Role conflict}

There is a fundamental conflict for some consultants between loyalty to the employer and loyalty to patients (and therefore one's obligations to the General Medical Council). The whole issue of whistle-blowing illustrates this well and our own Immediate Past Vice President has been through a conflict with her trust management over an issue which should have been left to her (clinical) discretion. The managers in this sorry affair were subsequently, and rather satisfactorily, censured by the Health Service Ombudsman then roasted by a parliamentary select 
committee and have now been recalled to give evidence again. But however much the outcome eventually vindicates the whistle-blower such events inevitably take a toll on the morale of even the most senior doctors.

Since this is a Professors of Psychiatry club lecture it is worth mentioning that academics have a further conflict between loyalty to clinical work demands and the performance indicators their universities require. At present you might have noticed that university psychiatrists are having a tougher time of it than their NHS counterparts. Not only has the university sector suffered real funding cuts year-on-year but the research of medical faculties has now also been rated as one of the worst of any academic subject in the higher education sector. This is a self-inflicted wound of enormous severity which is costing medical schools millions of pounds in lost funds for research support. So do not look to the academic cohort to lead the profession out of the morass of low morale.

\section{Poor social support}

The devolution of services and psychiatric manpower away from hospitals to the community has been blamed by some for reducing the opportunities for interaction with the peer group but I do not think this is inevitable. My impression is that those who do have good social support from a cohesive group of consultants have higher morale and that it is possible to create social structures for this to happen. However, the loss of the staff 'mess' has made it a good deal more difficult.

\section{Lack of feedback on job performance}

How many consultants have appraisals from their medical directors? Although junior doctors now expect to have such assessments every year, the status of 'independent practitioner' which comes with the Certificate of Completion of Specialist Training confuses the issue for consultants. You might ask what role the medical director could possibly have in supervising and appraising an independent practitioner'. Is not independence from trust management essential to avoid the pitfalls of high work demands, insufficient resources and role conflict? In fact, I believe the medical director is in a different position to other trust managers and that, far from avoiding appraisal, consultants should demand it every year together with proper job planning. This should focus on the consultant's personal development needs which must be seen in relation to their current job plan and their longer-term career intentions, as well as their performance in the previous year.

\section{Lack of influence over decisions at work}

Is the consultant responsible for planning the service or is the manager responsible? This dilemma often leaves doctors wondering how much influence they can still exert on the future shape of their services which they have built up on personal initiative over years and sometimes decades. In my experience managers often fail to make explicit the role they would like the doctor to play in planning and even when doctors' voices are heard they are often not heeded.

\section{Compromising professional standards}

We do this all the time by cutting corners because we do not have the time to do things properly. In particular, our patients (through user groups) tell us that we do not talk to them enough. Most patients do not want to have their counselling from one person and their drugs from another. They want their personal psychiatrist to talk to them about their problems as well as their tablets. This is also what most of us want to do but our contracts do not often allow us to do it.

In particular, the standard consultant job description has a catchment area or sector. This was trumpeted as the great achievement of the previous generation and indeed it stopped a lot of 'buck passing' of unpopular patients. But it has led to a situation in which we are now the only group of clinical consultants who take even a notional responsibility for the health of an entire population. That responsibility fits very poorly with the requirement to be a personal physician and it does not apply to any other profession in our multi-disciplinary teams or any other group of doctors, except public health and, in some respects, primary care. I would argue that psychiatry is now becoming too technical and demanding for this to go on and that we should develop job descriptions based on specialism. sessional commitments and case load which allow us to practise to the standard to which we are trained.

It would then become the responsibility of public health doctors and NHS managers to work out how to provide sufficient mental health professionals to treat the numbers of mentally ill in the population. That is the same as in any other speciality. If we continue to mix the public health and personal physician models we will continue to compromise professional standards and the gap between the ideal service and the real service will go on getting larger, driving morale down even further. 


\section{Cooperation, calculation and coercion}

While we are on the subject of contracts it is worth noting the idea of the psychological contract (Schein, 1980; Robinson \& Rousseau, 1994) and its influence on morale. Both legal and psychological contracts represent an agreement between the employer and the employee but while the former is written and explicit the latter is a set of mutual expectations which are more or less understood by both sides. There are three types. First, the cooperative contract is one in which staff are seen to be as important as management and institutional goals are negotiated rather than imposed. Staff have a high degree of autonomy and are facilitated by management. This is how it used to be for consultants in the NHS. Second, is the calculative contract in which the main motivations are assumed to be financial, more work for more pay. The suggestion of performancerelated pay is a very good example of this. It reduces medicine to a simple matter of selfinterest and is not how doctors like to think of their personal motivation. Under the calculative contract employee demands tend to increase and as they do so management begins to turn to the third kind of relationship, the coercive contract, in which services are given by the employee as a defence against unemployment or loss of salary. Often organisations using such contracts also require employees to wear uniforms, and apply rigid policies and procedures to control staff. Some of the characteristics of these last two psychological contracts may be familiar and may explain the suspicion of performance-related pay, confidentiality clauses (to prevent whistle-blowing) and clinical practice guidelines (Palmer, 1993). Some have argued (Northcott, 1996) that this shift from a cooperative towards a coercive contract reflects a loss of professional status and goes a long way towards explaining the catastrophic loss of morale in the service.

\section{The treatment}

But are things really so bleak or is this feeling a distortion arising from the mental state we have got ourselves into since 1990? If we can get the fundamentals right why should not psychiatrists have a high morale? Let us apply a little cognitive therapy to our hopelessness.

We are now delivering a system of care that we all believe in if only it was resourced properly. Community care was pioneered in psychiatry by psychiatrists. We will soon have got over the worst of the transition and now we are beginning to understand better how it should work. This drive into the community sustained the morale of a generation of pioneers who would have burnt out in mental hospitals. They believed they were making things better for their patients. But today, community care is 'old hat'. So what should sustain the enthusiasm of today's psychiatrists? It has to be the principle of the personal physician that successive Presidents have written and talked about (i.e. the use of the latest proven techniques to improve the welfare of individual patients). This to me is much more interesting and varied than the now mundane and non-medical arguments about where patients should live.

Our jobs are not under threat. We are statutorily indispensable because we are necessary for the Mental Health Act to function and we are the only members of the clinical team who can prescribe. So we cannot be 'skill-mixed' away. But to avoid being just 'coercive prescribers' we need to protect our position as personal physicians in all aspects of the role.

Our discipline is expanding rapidly. Although we are still too few there are more of us all the time. You cannot say that of all medical disciplines. Medical students are more and more interested in psychiatry and in spite of our very public problems recruitment to senior house officer posts is holding up - just about.

Public interest in psychiatry and mental health has increased dramatically over the past decade. Stigma still obviously exists but less so now and the College can take some of the credit for this. Our subject is a key area in Health of the Nation and remains a Government priority, for the time being.

Basic and applied science is improving in both the biological and the psychological aspects of care. Increasingly, psychiatric papers find their way into general medical and scientific journals. This should enable us to feel that what we are offering is better than it used to be. But if we cannot get new treatments into practice because we cannot afford the time to learn about them, or we feel there is no money to support them, then the new knowledge simply opens the gap between the ideal and the real services, damaging morale even further.

There are encouraging signs that the profession is regaining the initiative in planning services. Indeed 'planning' has now been replaced by 'market' in the NHS lexicon of dirty words. We must now use our expertise in the College to influence planning at regional and local level in addition to the national level at which we have always worked.

Continuing professional development is crucial to most of these suggestions. It has a general effect of allowing over-conscientious consultants to leave their clinics to refresh themselves professionally. It has the more specific effects of providing courses to teach effective interventions, and there is nothing like helping a patient 
get better to improve your morale. More specifically the splendid issue of Advances in Psychiatric Treatment on the health of doctors (September 1997) was a valuable contribution.

\section{Formulation}

So, in conclusion, what kind of mental state are we in? I think it is like the depressed patient whose relatives are saying she is getting better but who cannot yet perceive the improvement in herself. We are insecure about our effectiveness, made to feel guilty by complaining patients, trying too hard to be perfect, while perceiving our imperfections in the gap between the ideal and the real services we offer. But, as we often say to our depressed patients you have been well so you can get better'. Perhaps the new Government is already addressing some of these issues. As they say 'things can only get better'.

\section{Acknowledgements}

I am indebted to Hamid Ghodse for arranging the meeting of the Professors of Psychiatry club and to many of the College staff and colleagues who assisted in the collection of such data as we have available.

\section{References}

BORRLL, C. S., WALL, T. D., WEST, M. A., et al (1996) Mental Health of the Workforce in NHS Trusts. Phase 1 Final Report. Report to the Department of Health. Sheffield: Sheffield Institute of Work Psychology.

KENDELL, R. E. \& PEARCE, A. (1997) Consultant psychiatrists who retired prematurely in 1995 and 1996. Psychiatric Bulletin, 21, 741-745.

NoRTHCOTT, N. (1996) Contracts for good morale. Nursing Management, 3, 23.

PALMER, S. (1993) $Z$ and the art of management. Nursing Standard, 33, 45-47.

RoBINSON, S. \& RouSSEAU, D. (1994) Violating the psychological contract: not the exception but the norm. Joumal of Organisational Behaviour, 15, 245-259.

SCHEIN, E. (1980) Organisational Psychology. London: Prentice-Hall.

Chris Thompson, Professor of Psychiatry, Mental Health Group, University of Southampton, Royal South Hants Hospital, Brintons Terrace, Southampton SO14 OYG

\title{
Consultant psychiatrists' views on the supervision register
}

\author{
Francesca L. Lowe-Ponsford, Paul Wolfson and James Lindesay
}

\begin{abstract}
A questionnaire on attitudes to the supervision register, about one year after its introduction, was sent to all consultant psychiatrists identfied as working in the National Health Service South Thames Region. A response rate of $72.3 \%$ was obtained. Half of the respondents felt that the supervision register was not likely to reduce the risk of violence to the public by mentally disordered people and a quarter was unsure. Just over half felt confident in predicting violence, and over half felt that they had been reasonably trained to do so. Most had not changed their practice in admitting or discharging patients, or in the use of the Mental Health Act. There were criticisms of the register, for example: lack of resources needed to implement it, increased paperwork, stigmatisation of patients and the lack of a formal appeal mechanism. Fifty per cent felt
\end{abstract}

the register should be abolished, only $25.5 \%$ felt it should not be.

Following a series of homicides by mentally ill patients, there has been increasing media attention on a small group of patients - those who are mentally ill and are at increased risk to others. In response to public concern, the NHS Executive produced several proposals including the introduction of a supervision register. The guidelines for this were issued in February 1994 (National Health Service Management Executive, 1994), and required implementation beginning from April 1994. 